\title{
Variation in vertical stress in the Baram Basin, Brunei: tectonic and geomechanical implications
}

\author{
M.R.P. Tingay ${ }^{*}$, R.R. Hillis ${ }^{1}$, C.K. Morley $^{2}$, R.E. Swarbrick ${ }^{3}$ and E.C. Okpere ${ }^{4}$ \\ ${ }^{1}$ National Centre for Petroleum Geology and Geophysics, Adelaide University, Australia. \\ mtingay@ncpgg.adelaide.edu.au, fax: (+61) 883034345. \\ ${ }^{2}$ Department of Petroleum Geoscience, University of Brunei Darussalam, Bandar Seri \\ Begawan, Negara Brunei Darussalam. \\ ${ }^{3}$ Department of Geological Sciences, Durham University, Durham, United Kingdom. \\ ${ }^{4}$ Brunei Shell Petroleum, Seria, Negara Brunei Darussalam.
}

\begin{abstract}
The vertical or lithostatic stress is an important factor in tectonic and geomechanical studies and is commonly used in the prediction of pore pressures and fracture gradients. However, the vertical stress is not always calculated in-situ and the approximation of $1.0 \mathrm{psi} / \mathrm{ft}(22.63 \mathrm{MPa} / \mathrm{km})$ is often used for the vertical stress gradient. Vertical stress has been determined in 24 fields in the Baram Basin, Brunei, using density log and checkshot velocity survey data. The Baram Basin shows a variation in vertical stress gradient between 18.3-24.3 MPa/km at $1500 \mathrm{~m}$ depth below the surface. This variation has a significant effect on in-situ stress related issues in field development such as wellbore stability and fracture stimulation. The variation is caused by a bulk rock density change of $2.48-2.07 \mathrm{~g} / \mathrm{cm}^{3}$ from the hinterland of the delta to its front. Differential uplift and erosion of the delta
\end{abstract}

\footnotetext{
${ }^{*}$ Corresponding author
} 
hinterland and undercompaction associated with overpressure are the interpreted causes of the density and hence vertical stress variation.

\section{Keywords: Vertical Stress, Uplift, Brunei}

\section{INTRODUCTION}

Since Dickinson's (1953) classic paper on Gulf Coast pressure, it has been commonplace to adopt a value of $2.3 \mathrm{~g} / \mathrm{cm}^{3}$ for the mean density of sedimentary rocks, especially in Tertiary deltas. The popularity of this value is partly due to the fact that the resulting overburden stress gradient is $1.0 \mathrm{psi} / \mathrm{ft}(22.6 \mathrm{MPa} / \mathrm{km})$. However, we demonstrate that the vertical stress in sedimentary basins, indeed even in a Tertiary delta such as the Baram Basin, can vary greatly and should always be accurately determined using in-situ data. We suggest that the vertical stress variation within the Baram Basin is primarily related to uplift but is also influenced by secondary factors such as undercompaction associated with overpressure. Herein, we discuss the geological setting of the Baram Basin, our method for calculating the vertical stress and the vertical stress variation across the basin. We then show that the vertical stress variation is related to bulk density changes related to uplift and also describe the importance of accurately calculating vertical stress in tectonic studies, well design, fracture stimulation and the prediction of pore pressure and fracture gradient.

\section{REGIONAL GEOLOGY}

The Baram Basin of Brunei Darussalam (Figure 1) is not a classic Tertiary Delta deposited upon a passive margin such as the Mississippi and Niger Deltas. The Late 
Neogene Baram Basin is composed of several rapidly prograding delta systems built outwards from the Crocker-Rajang accretionary complex and deposited adjacent to the northwest Borneo active margin (Koopman \& James, 1996a). The active tectonic setting has resulted in a complex interaction between sedimentation and tectonics with variable uplift of the hinterland, sediment reworking and fast deposition rates. Transpressive deformation associated with the active margin has caused uplift in the proximal and eastern parts of the basin (Koopman \& James, 1996b; Figure 2). Uplifted sediments are eroded, reworked and deposited further down the delta. Deposition rates within the Baram Basin have reached $3000 \mathrm{~m} / \mathrm{Ma}$ (Koopman \& James, 1996b). Rapid deposition of the fine-grained prodelta sediments has led to the development of widespread overpressures generated by disequilibrium compaction (Schreurs \& Ellenor, 1996). Overpressures within the prodelta shales are commonly associated with undercompaction and shale diapirism (Schreurs \& Ellenor, 1996).

\section{METHODOLOGY}

Precise knowledge of the vertical stress magnitude has become very important in drilling operations, particularly in deepwater areas and in regions with high magnitude or shallow overpressures (Bruce, Borel \& Bowers, 2002; Traugott, 1997). The vertical or overburden stress $\left(\sigma_{\mathrm{v}}\right)$ at a specified depth is defined as the pressure exerted by the weight of the overlying rocks and expressed as (Engelder, 1993):

$$
\sigma_{\mathrm{v}}=\int_{\mathrm{z}}^{0} \rho(\mathrm{z}) \mathrm{g} \mathrm{dz}
$$

where

$\rho(z)=$ density of the overlying rock column at depth $z$ 
$\mathrm{g}=$ acceleration due to gravity.

The vertical stress in offshore wells is equal to the pressure exerted by the weight of the water column from the surface to the seabed plus the weight of the sediment column at a specified depth. Hence, the vertical stress at any depth is easily calculated by integrating the density log from the surface (or seabed). However, before calculating the vertical stress three issues must be addressed (Bell, 1996).

(i) The density log must be correctly formatted.

(ii) The density log must be filtered to remove spurious data.

(iii) The average density from the surface to the top of the density log must be estimated.

\section{Density log format}

The depth scale on petrophysical logs is generally recorded relative to the distance along the hole below the rotary table. In deviated wells the 'measured' depth is greater than the true vertical depth below the surface. Hence, the calculated vertical stress is underestimated if the effect of wellbore deviation and the height of the rotary table above the surface are not taken into account.

\section{Removing spurious data from the density log}

The density-logging tool needs to contact the wellbore wall firmly to yield accurate measurements (Asquith \& Gibson, 1982). The density logging tool measures the amount of scattered gamma rays a fixed distance from the gamma ray source. If the hole is rugose and contact is poor, the gamma rays are partially scattered by the low density fluids in the wellbore as well as the wall rock. Hence, density logs commonly 
show spuriously low values in sections of irregular borehole, which must be removed prior to calculating the vertical stress. We first used the density log correction curve (DRHO) to isolate spurious density measurements. Density data was assumed to be inaccurate where the corresponding DRHO value is greater than $0.2 \mathrm{~g} / \mathrm{cm}^{3}$ (Asquith \& Gibson, 1982).

The caliper log provides an alternative measure of borehole rugosity. If the caliper is greater than $\pm 5 \%$ of the bit size, density data is assumed to be affected by the rugose hole, and is removed.

A combination of filtering using DRHO and caliper data has been applied to all density data used in this study. Filtered density logs were also 'de-spiked' and edited manually to remove any anomalous measurements. Finally, the density log was smoothed and re-sampled prior to calculating the vertical stress.

\section{Estimating the average density from the surface to the top of the density log}

Density logs are generally not run all the way to the surface (or seabed in offshore wells). In order to calculate the vertical stress it is necessary to first estimate an average density from the surface to the top of the density log. There are several methods proposed for estimating the bulk density from the surface to the top of the density log, such as:

- measuring bulk density from shallow sediment cores (Niemann, 2002);

- downhole gravimetry;

- basin modelling;

- regional density versus depth trends (Traugott, 1997); 
- compressional-wave (sound) velocity versus density trends (Ludwig, Nafe \& Drake, 1970; Gardner, Gardner \& Gregory, 1974; Hamilton, 1978), and; - compressional-wave velocity to porosity and porosity to density transforms.

The importance of accurately calculating the vertical stress magnitude in some regions has resulted in very careful measurement of shallow densities by either direct measurement from geotechnical cores or from shallow downhole gravimetry. However, these techniques are rarely performed and have not been undertaken in Brunei. Basin modelling can also be used to estimate the density of shallow sediments. Unfortunately, data is not available to use basin modelling to estimate the density from the surface to the top of the log in this study. Traugott (1997) suggests determining a regional density versus depth trend to estimate density from the surface to the top of the density log. However, we show herein that bulk density across Brunei varies significantly from field to field and hence, a regional density trend is not appropriate. Therefore, the only techniques feasible for this study involve using the compressional-wave velocity to estimate the bulk density from the surface to the top of the density $\log$.

Sonic velocity and density are strongly related and there are many techniques for estimating bulk density from the compressional-wave velocity. The average compressional-wave velocity between the surface (or seabed in offshore wells) and the top of the density log can be determined from checkshot velocity survey data. Checkshot velocity surveys are routinely performed in most fields and the data were available for all wells assessed in this study. Three methods of estimating the average 
density from the surface to the top of density logs using compressional-wave velocity have been tested and compared for the Brunei data. These methods are:

- the Nafe-Drake sonic velocity to density transform (Ludwig et al., 1970);

- the Gardner sonic velocity to density transform (Gardner et al., 1974), and;

- using sonic velocity to estimate porosity and then converting porosity to bulk density.

Nafe-Drake and Gardner sonic velocity to density transforms The Nafe-Drake and Gardner sonic velocity to density transforms are empirically derived relationships from laboratory measurements of core samples and downhole sonic and density log data. Both transforms are still widely used and give good generalisations of the velocity-density relations in sea-floor sediments (Hamilton, 1978). Both the Gardner and Nafe-Drake transforms have been determined from sediments worldwide to yield main trends (known as the Gardner and Nafe-Drake correlations respectively; Figure 3). Sonic log velocities from the Baram Basin have been used to generate re-calibrated Nafe-Drake and Gardner curves for each individual field. These correlations were re-calibrated by cross-plotting all density and sonic data within a field and laterally shifting the Nafe-Drake curve to pass through the average sonic velocity/density value (Figure 3 ). The recalibrated NafeDrake and Gardner correlations were then used to convert the average velocity to the top of the density log to an average density.

Sonic velocity to porosity and porosity to density transforms 
Both sonic velocity and density data are commonly used to estimate porosity in sedimentary rocks. Porosity $(\phi)$ can be estimated from the bulk density by the following relationship (Asquith \& Gibson, 1982):

$$
\phi=\left(\rho_{\mathrm{ma}}-\rho_{\mathrm{b}}\right) /\left(\rho_{\mathrm{ma}}-\rho_{\mathrm{f}}\right)
$$

where

$\rho_{\mathrm{ma}}=$ matrix (or grain) density.

$\rho_{\mathrm{b}}=$ bulk density.

$\rho_{\mathrm{f}}=$ pore fluid density.

Equation 2 can be rearranged to yield an estimate for bulk density in terms of matrix density, pore fluid density and average porosity. The average matrix density measured from nine core plugs in Brunei is $2.72 \mathrm{~g} / \mathrm{cm}^{3}$. The fluid density is assumed to be 1.01 $\mathrm{g} / \mathrm{cm}^{3}$. The average sediment porosity between the surface and the top of the density log was estimated herein by means of a corrected Wyllie time average equation (Raymer, Hunt \& Gardner, 1980) of the form:

$$
\phi=\left(1 / \mathrm{C}_{\mathrm{p}}\right)\left(\Delta \mathrm{t}-\Delta \mathrm{t}_{\mathrm{ma}}\right) /\left(\Delta \mathrm{t}_{\mathrm{f}}-\Delta \mathrm{t}_{\mathrm{ma}}\right)
$$

where

$\mathrm{Cp}=$ correction factor for unconsolidated sediments.

$\Delta \mathrm{t}=$ sediment compressional wave-velocity (herein the average velocity between the surface or seabed and the top of the density log).

$\Delta \mathrm{t}_{\mathrm{ma}}=$ matrix (or grain) velocity. 
$\Delta \mathrm{t}_{\mathrm{f}}=$ pore fluid velocity.

The original Wyllie time average equation states that the travel time of a compressional wave in rock is simply the sum of the travel times through the solid and fluid components of the rock (Wyllie, Gregory \& Gardner, 1956). However, the original Wyllie relationship was determined in consolidated sandstones and overestimates the porosity of shales and unconsolidated sediments. Raymer et al. (1980) suggests applying a correction factor to better estimate the porosity in shales and unconsolidated sediments. However, Dvorkin \& Nur (1998) show that the corrected Wyllie time average equation will still overestimate porosity and thus should not be used in unconsolidated sediments. The porosity of shallow, unconsolidated sediments can be more accurately estimated from relationships such as scaled or modified Hashin-Shtrikman bounds (Nur, Mavko, Dvorkin \& Galmudi, 1998; Prasad \& Dvorkin, 2001). However, these methods require laboratory-derived data on bulk and shear moduli that are not available for this study. The improved Wyllie time-average equation has been used previously to estimate porosities in Brunei (Tingay, Hillis, Swarbrick, Mildren, Morley \& Okpere, 2000). Tingay et al. (2000) calculated a correction factor of 2.16 and a matrix velocity of $169 \mu \mathrm{s} / \mathrm{m}$ and assumed a pore fluid velocity of $613.5 \mu \mathrm{s} / \mathrm{m}$ for Brunei. Nur et al. (1998) notes that the corrected Wyllie time-average equation can give accurate estimates for porosity when deterministically fitted to a dataset. Hence, the Tingay et al. (2000) corrected Wyllie time-average equation determined for Brunei is cautiously used herein to estimate porosity and subsequently bulk density between the surface and the top of the density log (herein referred to as the 'Wyllie technique'). 


\section{Discussion}

Density estimates from the Wyllie technique are compared with the density estimates from the Nafe-Drake and Gardner transforms to determine which method is most accurate. The Nafe-Drake, Gardner and Wyllie techniques have been used to estimate the average densities of sediments between the surface (or seabed for offshore wells) and the top of the density log for the 24 wells in this study (Table 1). There is only a small variation in the densities estimated by each of the three techniques in each well (Table 1). The largest difference between estimated average densities in a single well using each of the three techniques is $0.37 \mathrm{~g} / \mathrm{cm}^{3}$. The difference in estimated average densities using all three techniques is less than $0.2 \mathrm{~g} / \mathrm{cm}^{3}$ in each of the other 23 wells. The largest variations in estimated density occur in wells with density logs starting at shallow depths. More significantly, the estimates of vertical stress at the top of the density log are also comparable for each density estimation technique. The largest difference in estimated vertical stress calculated at the top of the log is $1.3 \mathrm{MPa}$ and there is less than $0.5 \mathrm{MPa}$ difference in estimated vertical stress in all but two wells (Table 1). As expected, the greatest variation in estimated vertical stress at the top of the density log is in the wells with the largest interval between the surface (or seabed) and the top of the density log.

Two of the 24 wells have density logs starting at the surface (or seabed) and therefore could be used to determine the errors associated with each density estimation technique. One well is located inland approximately 60 kilometres from the coast and the other well is located two kilometres offshore. The Wyllie, Gardner and NafeDrake techniques were used to estimate the average density and vertical stress magnitude at 100, 200, 300, 500, 750, 1000 and 1300 metres depth in these two wells. 
The estimated average densities and vertical stress magnitudes were then compared to the measured average densities and vertical stress magnitudes calculated directly from the density logs. The largest error in density for all three techniques was only 0.18 $\mathrm{g} / \mathrm{cm} 3$ (at $100 \mathrm{~m}$ depth) and the average error in density estimates was $0.06 \mathrm{~g} / \mathrm{cm} 3$ (Figure 4a). The greatest error in vertical stress estimate from the three techniques was $0.83 \mathrm{MPa}$ at $1300 \mathrm{~m}$ depth (Figure 4b). However, for depths of less than $1000 \mathrm{~m}$ the estimate of vertical stress from the Nafe-Drake, Gardner and Wyllie techniques was less than $0.5 \mathrm{MPa}$ and the average error was just 0.25 MPa. The Nafe-Drake and Gardner techniques are more accurate at depths of $1000 \mathrm{~m}$ or less and the Wyllie method was the most accurate method at $1300 \mathrm{~m}$ depth. Herein the re-calibrated NafeDrake technique is favoured as it has the overall lowest average error and standard deviation of the three techniques. Hence, the re-calibrated Nafe-Drake technique is used to estimate the average density between the surface and top of the density log in this study.

The aim of this paper is to show that there is a large vertical stress variation across Brunei and that this is related to a variation in bulk density across the delta. Therefore, it is important to show that the observed vertical stress variation cannot be caused by errors in the estimation of average density from the surface to the top of the density log. Of the 24 wells in this study 15 wells have the density log starting at less than $180 \mathrm{~m}$ below the surface or seabed. At such shallow depths even a very large error in estimated density such as $0.5 \mathrm{~g} / \mathrm{cm}^{3}$ would result in an error in the vertical stress magnitude of only $0.88 \mathrm{MPa}$ (Figure 5). Of the other nine wells in this study only three wells have the top of the density log starting at greater than $530 \mathrm{~m}$ below the surface (or seabed). The estimated density from the surface to the top of the log 
improves with depth (Figure 4a). Yet, even a large error in estimated density between the top of the $\log$ and the surface of $0.2 \mathrm{~g} / \mathrm{cm}^{3}$ would result in an error in vertical stress magnitude of $2.55 \mathrm{MPa}$ at $1300 \mathrm{~m}$ depth (Figure 5). In the following section we show that the vertical stress at $1500 \mathrm{~m}$ depth below the surface or seabed varies by 6.0 $\mathrm{MPa}$ across Brunei. Hence, even with grossly overestimated errors the variation in vertical stress across Brunei cannot be accounted for by errors in estimating the density between the surface and the top of the density log.

\section{RESULTS}

The vertical stress magnitude was calculated for wells within 24 fields throughout the onshore and offshore Baram Basin (Figure 6). Hereafter, values of vertical stresses are referred to and plotted as gradients for easier comparison between fields and for clarity (Figure 7). Vertical stress gradients vary with depth in individual fields and also between fields. Figure 8 shows a contour map of the vertical gradients at $1500 \mathrm{~m}$ depth over the Baram Basin. Gradients at $1500 \mathrm{~m}$ depth vary from $18.3 \mathrm{MPa} / \mathrm{km}$ in the distal parts of the delta to $24.3 \mathrm{MPa} / \mathrm{km}$ in the hinterland (Figure 2).

The variation in vertical stress gradients suggests that bulk density changes across the delta. However, in offshore regions the vertical stress is the pressure exerted by the rock column and the column of water extending from the surface to the sea floor (Traugott, 1997). Hence, before relating the vertical stress to actual rock density the effect of water depth must first be removed. The depth to seabed in the wells studied varies from 0-413 $\mathrm{m}$ and the general bathymetry of offshore Brunei mirrors the vertical stress gradient contours in Figure 8. The effect of water depth is removed by subtracting the weight of the water column from the calculated vertical stress and 
subtracting water depth from the depth below sea level to give depth below sea floor. The vertical stress below sea floor is the pressure exerted by the rock column only and is solely function of the bulk rock density. The vertical stress below sea floor is plotted herein purely to highlight variations in bulk density across the basin. For geomechanical applications the vertical stress should always be determined from the surface. Figure 9 shows the vertical stress gradients calculated for $1500 \mathrm{~m}$ below sea floor (or below surface for onshore wells). Sub-seabed vertical stress gradients vary from 20.3 to $24.3 \mathrm{MPa} / \mathrm{km}$, which represents a variation in bulk crustal density between $2.07-2.48 \mathrm{~g} / \mathrm{cm}^{3}$.

It is commonly assumed in passive margin settings that the vertical stress and minimum horizontal stress $\left(\sigma_{\mathrm{hmin}}\right)$ magnitudes are related by Poisson's ratio $(v)$ by the equation (Engelder, 1993):

$$
\sigma_{\text {hmin }}=(v / 1-v) \sigma_{v}
$$

In passive margin settings it might be expected that a large variation in vertical stress magnitude would be accompanied by a corresponding variation in horizontal stress magnitude (commonly estimated from leak-off pressures and fracture tests). However, variations in the minimum horizontal stress magnitude are controlled much more by pore pressure and tectonic stress than variations in the vertical stress magnitude (Engelder, 1993; Hillis, 2001). The Baram Basin is not a passive margin setting and high magnitude overpressures are observed in most fields. Therefore, the variation in vertical stress magnitude in Brunei is unlikely to be accompanied by an observable variation in minimum horizontal stress magnitude. Hence, the Poisson's ratio 
relationship was not used in this study to confirm the variation in vertical stress magnitude.

\section{ORIGIN OF VARIATION IN VERTICAL STRESS}

The likely cause of the bulk crustal density variation in the Baram Basin is large-scale uplift and erosion of the hinterland associated with the northwest Borneo active margin (Koopman \& James, 1996a). The deltaic sediments are derived from the uplifted Crocker-Rajang accretionary range. These sediments have been buried and compacted with a resultant increase in density with depth. However, throughout the Miocene and Pliocene, sections of the hinterland have been inverted and uplifted, in particular the Belait, Seria and Champion Fields (Koopman, Schreurs \& Ellenor, 1996; Watters, Maskall, Warrilow \& Liew, 1999). Uplift and unloading does not reverse sediment compaction. In the uplifted regions the less dense upper section has been eroded away leaving denser material nearer to the surface. Thus, sediments in the hinterland of the Baram Basin are more compacted and denser than sediments at the same depth in distal parts of the delta. Hence, there is a corresponding decrease in vertical stress from onshore to offshore sections of the delta.

The variation in vertical stress across the delta has been generated to a lesser extent by local factors such as overpressure and localised differential uplift. Disequilibrium compaction overpressures in the Baram Basin are associated with undercompaction and abnormally low densities (Figure 10). Well A (Figure 9) intersected an overpressured and undercompacted shale diapir at approximately $1000 \mathrm{~m}$ below sea level ( $\approx 600 \mathrm{~m}$ below sea floor). The associated low density sediments result in the very low vertical stress in Well A. Localised differential uplift has caused small 
variations in vertical stress gradients within some areas. The variation in vertical stress gradients between the Champion Main and Champion West Fields (Figure 9) is associated with Late Miocene/Early Pliocene differential uplift and erosion of the Champion region (Koopman et al., 1996). Uplift of the Champion area varies between $600 \mathrm{~m}$ in Champion West to $1500 \mathrm{~m}$ in Champion Main (de Bree, Hydendaal \& van de Hoek, 1993). This has resulted in a variation in vertical stress gradients from 21.9-22.6 MPa/km at $1500 \mathrm{~m}$ below sea floor in the Champion area.

\section{GEOMECHANICAL IMPLICATIONS}

The variation in bulk crustal densities and hence vertical stress across the Baram Basin has significant geomechanical implications. It has been often assumed for the Gulf of Mexico and other Tertiary deltas that vertical stress can be approximated as having a gradient of $1.0 \mathrm{psi} / \mathrm{ft}$ or $22.63 \mathrm{MPa} / \mathrm{km}$ (Dickinson, 1953). Assuming a vertical stress gradient of $1.0 \mathrm{psi} / \mathrm{ft}$ for the Baram Basin results in errors in any geomechanical analysis such as fracture stimulation, wellbore stability, fracture gradient prediction and pore pressure prediction, as discussed below.

\section{Fracture Stimulation}

In normal $\left(\sigma_{\mathrm{v}}>\sigma_{\mathrm{H}}>\sigma_{\mathrm{hmin}}\right)$ or strike-slip $\left(\sigma_{\mathrm{H}}>\sigma_{\mathrm{v}}>\sigma_{\mathrm{hmin}}\right)$ fault regimes fractures hydraulically induced to stimulate hydrocarbon recovery are vertical and orthogonal to $\sigma_{\mathrm{h}}$. In reverse fault regimes $\left(\sigma_{\mathrm{H}}>\sigma_{\mathrm{hmin}}>\sigma_{\mathrm{v}}\right)$ hydraulic fractures are horizontal. Horizontal fractures may not provide the desired improvement in permeability (horizontal permeability generally being greater than vertical permeability; Clennell, Dewhurst, Brown \& Westbrook, 1999). In reverse fault regimes hydraulic fractures may also twist from vertical at the wall of a vertical wellbore to horizontal as they 
propagate into the far-field with concomitant loss of permeability and potential proppant screen out (Roberts, Chipperfield \& Miller, 2001).

No horizontal stress magnitudes are yet available for the toe of the Baram Delta, a deep water area of current exploration focus. However, active thrusting apparent on seismic data suggests the current stress regime is reverse $\left(\sigma_{H}>\sigma_{h m i n}>\sigma_{v}\right)$ and hydraulically-induced fractures may be horizontal (Koopman \& James, 1996a; Figure 2). Hence, fracture stimulation may be an unsuccessful development option in the area. Detailed determination of the in-situ stress regime at the toe area will need to recognise the low vertical stress in the area, of $18.3 \mathrm{MPa} / \mathrm{km}(0.81 \mathrm{psi} / \mathrm{ft}$; Figure 9$)$. Assuming a $1.0 \mathrm{psi} / \mathrm{ft}(22.63 \mathrm{MPa} / \mathrm{km})$ vertical stress gradient, horizontal stress gradients of 18.3-22.6 MPa/km would be taken to imply a normal or strike-slip fault regime, whereas in fact such horizontal stress magnitudes would indicate a reverse fault regime $\left(\sigma_{\mathrm{H}}>\sigma_{\mathrm{hmin}}>\sigma_{\mathrm{v}}\right)$ in the delta toe area.

\section{Wellbore Stability}

An accurate calculation of the vertical stress magnitude is required to assess the stability of deviated wellbores. For example, highly deviated boreholes are more prone to borehole breakout than vertical boreholes in a normal fault stress regime. However, vertical boreholes are most prone to breakout in a strike-slip stress regime (Hillis \& Williams, 1993). Borehole stability is a serious concern in well design. If a proposed deviated borehole is incorrectly predicted to be breakout prone, it is likely that the target will be drilled using a different and more expensive well design than necessary. Estimating rather than calculating the vertical stress magnitude could result in unreliable borehole stability prediction. 


\section{Fracture Gradient Prediction}

The fracture gradient relation is commonly determined during well design to identify the maximum mud weight that can be used without fracturing the formation. Fracture gradient relationships are determined with respect to the vertical stress magnitude and are of the form (Traugott, 1997):

$$
\sigma_{\mathrm{hmin}}=\mathrm{k} \sigma_{\mathrm{v}}+(1-\mathrm{k}) \mathrm{P}_{\mathrm{p}}
$$

where

$\sigma_{\mathrm{hmin}}=$ minimum horizontal stress magnitude

$\mathrm{P}_{\mathrm{p}}=$ Pore pressure

$\mathrm{k}=$ fracture gradient constant

If too large a value for vertical stress is used in equation 5 the fracture gradient is overestimated. For example, for a typical $\mathrm{k}$ value of 0.4 using a vertical stress gradient of $1.0 \mathrm{psi} / \mathrm{ft}(22.63 \mathrm{MPa} / \mathrm{km})$ instead of $20.0 \mathrm{MPa} / \mathrm{km}$ results in a 1.05 $\mathrm{MPa} / \mathrm{km}$ overestimate of the fracture gradient. The erroneously high predicted fracture gradient could result in expensive mud losses.

\section{Pore Pressure Prediction}

The Eaton (1972) method is commonly used for pore pressure prediction. However, the Eaton (1972) method (as well as equivalent depth methods) requires an accurate vertical stress magnitude. The formula for the Eaton (1972) method is: 


$$
\mathrm{P}_{\mathrm{p}} / \mathrm{z}=\sigma_{\mathrm{v}} / \mathrm{z}-\left(\sigma_{\mathrm{v}} / \mathrm{z}-\mathrm{P}_{\mathrm{n}} / \mathrm{z}\right) \times\left(\Delta \mathrm{t}_{\text {norm }} / \Delta \mathrm{t}_{\mathrm{obs}}\right)^{3.0}
$$

where

$$
\begin{aligned}
& \mathrm{P}_{\mathrm{p}} / \mathrm{z}=\text { Pore pressure gradient }(\mathrm{MPa} / \mathrm{km}) \\
& \mathrm{P}_{\mathrm{n}} / \mathrm{z}=\text { Hydrostatic pore pressure gradient }(\mathrm{MPa} / \mathrm{km}) \\
& \sigma_{\mathrm{v}} / \mathrm{z}=\text { Vertical stress gradient }(\mathrm{MPa} / \mathrm{km}) \\
& \Delta \mathrm{t}_{\text {norm }}=\text { Normal sonic log value }(\mu \mathrm{s} / \mathrm{ft}) \\
& \Delta \mathrm{t}_{\text {obs }}=\text { Observed sonic log value }(\mu \mathrm{s} / \mathrm{ft})
\end{aligned}
$$

Pore pressures are overestimated by the Eaton (1972) method if too large a vertical stress gradient is used. The magnitude of the error caused by using an incorrect vertical stress gradient depends on the difference between the observed and estimated sonic log values. The error increases if there is a greater difference between the observed and estimated sonic log value. The error caused by using an incorrect vertical stress gradient can be significant. For example, if a $1.0 \mathrm{psi} / \mathrm{ft}(22.63 \mathrm{MPa} / \mathrm{km})$ vertical stress gradient is assumed in a field with a $20 \mathrm{MPa} / \mathrm{km} \sigma_{\mathrm{v}}$ gradient (and using $\Delta \mathrm{t}_{\text {norm }}=120 \mu \mathrm{s} / \mathrm{ft}$ and $\Delta \mathrm{t}_{\mathrm{obs}}=90 \mu \mathrm{s} / \mathrm{ft}$ ) the pore pressure gradient would be overestimated by $1.5 \mathrm{MPa} / \mathrm{km}$.

\section{CONCLUSIONS}

Vertical stress varies both with depth in individual wells and also changes greatly across the Baram Basin. This variation is partially due to increasing water depth towards the northwest. However, after the weight of the water column is removed there is still a significant variation in vertical stress related to changes in bulk rock density across the basin. The primary cause for the rock density difference is 
interpreted to be the uplift and erosion of the delta hinterland. Undercompaction associated with disequilibrium compaction overpressure and localised differential uplift has a secondary affect on bulk density and vertical stress magnitude.

The vertical stress is easy to determine and is essential for tectonic and geomechanical studies. Using an assumed vertical stress magnitude can result in incorrect determination of the present-day stress regime that affect predictions for wellbore stability and fracture stimulation. An accurate vertical stress gradient is required in pore pressure prediction and fracture gradient determination. An incorrectly high estimate of vertical stress results in overestimation of both the pore pressure and fracture gradient. Accurate calculation of the vertical stress is important and should not be assumed, particularly in regions with differential uplift or high magnitude overpressures.

\section{ACKNOWLEDGEMENTS}

The authors would like to thank the Australian Research Council for funding this study. The authors would also like to thank Brunei Shell Petroleum and the Petroleum Unit for supplying the data used herein and for granting permission to publish these results.

\section{REFERENCES}

Asquith, G. B., \& Gibson, C. R. (1982). Basic well log analysis for geologists. Tulsa: American Association of Petroleum Geologists, p. 216.

Bell, J. S. (1996). In situ stresses in sedimentary rocks (part 1): measurement techniques. Geoscience Canada, 23, 85-100. 
de Bree, P., Hydendaal, H. G., \& van de Hoek P. J. (1993). Rock mechanical investigations for improved fracture closure gradient prediction, Champion Field, Brunei, Rijswijk, The Netherlands, Shell Internationale Research.

Bruce, B., Borel, R., \& Bowers G. (2002). Well planning for SWF and overpressures at the Kestrel well. The Leading Edge, 21, 669-671.

Clennell, M.B., Dewhurst, D.N., Brown, K.M., \& Westbrook, G.K. (1999). Permeability anisotropy of consolidated clays. Geological Society (London) Special Publication, 158, 79-96.

Dickinson, G. (1953). Geological aspects of abnormal reservoir pressures in Gulf Coast Louisiana. American Association of Petroleum Geologists Bulletin, 37, 410-432.

Dvorkin, J. \& Nur, A. (1998). Time-average equation revisited. Geophysics, 63, 460464.

Eaton, B. A. (1972). Graphical method predicts geopressures worldwide. World Oil, $182,51-56$.

Engelder, T. (1993). Stress Regimes in the Lithosphere. Princeton: Princeton University Press, p. 457.

Gardner, G. H. F., Gardner, L. W., \& Gregory, A. R. (1974). Formation velocity and density - the diagnostic basics for stratigraphic traps. Geophysics, 39, 770-780.

Hamilton, E. L. (1978). Sound velocity-density relations in sea-floor sediments and rocks. Journal of the Acoustical Society of America, 63, 366-377.

Hillis, R. R., \& Williams, A. F. (1993). The contemporary stress field of the BarrowDampier Sub-Basin and its implications for horizontal drilling. Exploration Geophysics, 24, 567-576.

Hillis, R. R. (2001). Coupled changes in pore pressure and stress in oil fields and 
sedimentary basins. Petroleum Geoscience, 7, 419-425.

Koopman, A., Schreurs, J., \& Ellenor, D. W. (1996). Chapter 5: The Oil and Gas Resources of Brunei Darussalam - The Coastal and Offshore Oil and Gas Fields. In S. T. Sandal (Ed.), The Geology and Hydrocarbon Resources of Negara Brunei Darussalam (pp. 155-192). Bandar Seri Begawan: Syabas.

Koopman, A., \& James, D. M. D. (1996a). Chapter 2: Regional Geological Setting. In S. T. Sandal (Ed.), The Geology and Hydrocarbon Resources of Negara Brunei Darussalam (pp. 49-63). Bandar Seri Begawan: Syabas.

Koopman, A., \& James, D. M. D. (1996b). Chapter 3: Structure. In S. T. Sandal (Ed.), The Geology and Hydrocarbon Resources of Negara Brunei Darussalam (pp. 64-80). Bandar Seri Begawan: Syabas.

Ludwig, W. E., Nafe, J. E., \& Drake, C. L. (1970). Seismic refraction. In A. E. Maxwell (Ed.), The Sea (pp. 53-84). New York: Wiley-Interscience.

Niemann, J. C. (2002). Developing a more rigorous methodology for the determination of pressure from resistivity measurements. In: Geopressure: Conceptual Advances, Applications, and Future Challenges SEG/EAGE workshop, Galveston 2002.

Nur, A., Mavko, G., Dvorkin, J., \& Galmudi, D. (1998). Critical porosity: a key to relating physical properties to porosity in rocks. The Leading Edge, 17, 357362.

Prasad, M., \& Dvorkin, J. (2001). Velocity to porosity transform in marine sediments. Petrophysics, 42, 429-437.

Raymer, L. L., Hunt, E. R., \& Gardner, J. S. (1980). An improved sonic transit time to-porosity transform. In: Society of Professional Wireline Log Analysts $21^{\text {st }}$ annual logging symposium, 1980.

Roberts, G. A., Chipperfield, S. T., and Miller, W. K. (2001). Evolution of a high 
near-wellbore pressure-loss-treatment strategy. Journal of Petroleum Technology, 53, 42-47.

Schreurs, J., \& Ellenor, D. W. (1996). Chapter 5: The Oil and Gas Resources of Brunei Darussalam - Hydrocarbon Habitat. In S. T. Sandal (Ed.), The Geology and Hydrocarbon Resources of Negara Brunei Darussalam (pp. 147-154). Bandar Seri Begawan: Syabas.

Tingay, M. R. P., Hillis, R. R., Swarbrick, R. E., Mildren, S. D., Morley, C. K., \& Okpere E. C. (2000). The sonic and density log expression of overpressure in Brunei Darussalam. In: Drilling and Exploiting Overpressured Reservoirs, Overpressure 2000 Workshop, London 2000.

Traugott, M. (1997). Pore/fracture pressure determinations in deep water. Deepwater Technology (Supplement to August 1997 World Oil and Pipe Line \& Gas Industry), 68-70.

Watters, D. G., Maskall, R. C., Warrilow, I. M., \& Liew, V. (1999). A sleeping giant awakened: further development of the Seria Field, Brunei Darussalam, after almost 70 years of production. Petroleum Geoscience, 5, 147-159.

Wyllie, M. R. J., Gregory, A. R., \& Gardner, L. W. (1956). Elastic wave velocities in heterogeneous and porous media. Geophysics, 21, 41-70. 


\section{TABLES}

\begin{tabular}{ccccccccc}
\hline $\begin{array}{c}\text { Depth to top of } \\
\text { density } \log (\mathrm{m})\end{array}$ & $\begin{array}{c}\text { Depth to } \\
\text { seabed }(\mathrm{m})\end{array}$ & $\begin{array}{c}\text { Seabed to top } \\
\text { of } \log (\mathrm{m})\end{array}$ & \multicolumn{2}{c}{ Nafe-Drake } & \multicolumn{2}{c}{$\begin{array}{c}\text { Gardner } \\
\rho_{\mathrm{av}} / \sigma_{\mathrm{v}}\end{array}$} & \multicolumn{2}{c}{ Wyllie } \\
$\rho_{\mathrm{av}} / \sigma_{\mathrm{v}}$ & \multicolumn{2}{c}{$\rho_{\mathrm{av}} / \sigma_{\mathrm{v}}$} \\
\hline 0 & 0 & 0 & - & 0 & - & 0 & - & 0 \\
9.8 & 9.8 & 0 & - & 0.1 & - & 0.1 & - & 0.1 \\
94 & 0 & 94 & 1.94 & 1.79 & 2.05 & 1.89 & 2.06 & 1.9 \\
95.9 & 42.4 & 53.5 & 1.95 & 1.44 & 2.04 & 1.49 & 2.06 & 1.5 \\
98.8 & 37 & 61.8 & 2.02 & 1.59 & 2.09 & 1.63 & 2.10 & 1.64 \\
108 & 41.3 & 66.7 & 2.08 & 1.77 & 2.16 & 1.82 & 2.19 & 1.84 \\
114.6 & 23.5 & 91.1 & 1.95 & 1.98 & 2.05 & 2.07 & 2.08 & 2.09 \\
132 & 71 & 61 & 1.69 & 1.72 & 1.89 & 1.83 & 2.07 & 1.94 \\
141.9 & 80.3 & 61.6 & 2.00 & 2.01 & 2.11 & 2.07 & 2.06 & 2.04 \\
161.9 & 90 & 71.9 & 1.93 & 2.25 & 2.07 & 2.35 & 1.94 & 2.26 \\
207.9 & 99.5 & 108.4 & 2.06 & 3.18 & 2.15 & 3.27 & 2.07 & 3.18 \\
225 & 106.7 & 118.3 & 2.03 & 3.41 & 2.13 & 3.53 & 2.05 & 3.44 \\
229.7 & 72 & 157.7 & 2.07 & 3.92 & 2.19 & 4.1 & 2.02 & 3.83 \\
232 & 71 & 161 & 1.89 & 3.69 & 2.02 & 3.9 & 1.98 & 3.83 \\
238.2 & 62.7 & 175.5 & 1.85 & 3.81 & 2.01 & 4.07 & 2.01 & 4.08 \\
259.4 & 24.3 & 235.1 & 2.18 & 5.25 & 2.25 & 5.42 & 2.13 & 5.16 \\
426 & 54 & 372 & 1.92 & 7.55 & 2.06 & 8.05 & 2.01 & 7.87 \\
520 & 0 & 520 & 2.31 & 11.73 & 2.30 & 11.78 & 2.36 & 12.04 \\
600 & 98 & 502 & 1.98 & 10.69 & 2.08 & 11.2 & 2.03 & 10.96 \\
611 & 378 & 233 & 1.93 & 8.15 & 2.07 & 8.46 & 1.94 & 8.18 \\
710 & 47.6 & 662.4 & 2.06 & 13.84 & 2.14 & 14.36 & 2.10 & 14.11 \\
718 & 413 & 305 & 1.95 & 9.92 & 2.09 & 10.34 & 1.94 & 9.89 \\
930 & 49.6 & 880.4 & 2.11 & 18.72 & 2.15 & 19.05 & 2.20 & 19.46 \\
1317 & 0 & 1317 & 2.17 & 28.04 & 2.18 & 28.19 & 2.27 & 29.36 \\
\hline
\end{tabular}

Table 1: Estimated average densities $(\mathrm{g} / \mathrm{cm} 3)$ and vertical stress magnitudes (MPa)

from the surface to the top of the density log using the Nafe-Drake, Gardner and

Wyllie methods. 


\section{FIGURE CAPTIONS}

Figure 1: Map of northern Borneo showing location of Baram Basin, Crocker-Rajang accretionary Complex and the northwest Borneo active margin (expressed in the present-day by the outer zone of thrusting and the northwest Borneo trough).

Figure 2: Schematic geological cross-section across the Baram Basin (adapted from Koopman \& James, 1996a). The delta hinterland has been uplifted and eroded. Vertical stress gradients at $1500 \mathrm{~m}$ depth vary from $18.3 \mathrm{MPa} / \mathrm{km}$ in the distal parts of the delta to $24.3 \mathrm{MPa} / \mathrm{km}$ in the hinterland.

Figure 3: Re-calibrated Nafe-Drake and Gardner correlations. The Nafe-Drake and Gardner correlations are calibrated for each field by laterally shifting the original curves through the average sonic and density log value in the field.

Figure 4: Two wells with density logs run from the surface are used to test the accuracy of the Nafe-Drake, Gardner and Wyllie methods. The Nafe-Drake, Gardner and Wyllie methods are used to estimate: (a) the average density and (b) vertical stress magnitude between the surface and different depths down to $1300 \mathrm{~m}$. The estimated average densities and vertical stress magnitudes are then compared with measured densities and vertical stress magnitudes calculated directly from the density logs. The Average density was estimated to within $\pm 0.18 \mathrm{~g} / \mathrm{cm}^{3}$ and vertical stress magnitude to within $\pm 0.83 \mathrm{MPa}$ for all three estimation methods. 
Figure 5: Sensitivity of vertical stress magnitude to erroneous estimates of average density between the surface and the top of the density log. Extremely large errors in estimated density $\left(0.5 \mathrm{~g} / \mathrm{cm}^{3}\right.$ error if top of density $\log <180 \mathrm{~m}$ depth and $0.2 \mathrm{~g} / \mathrm{cm}^{3}$ error if top of $\log >180 \mathrm{~m}$ depth) cannot cause errors large enough to account for the observed variation in vertical stress magnitude across Brunei.

Figure 6: Calculated vertical stress magnitudes over the Baram Basin. Vertical stress varies with depth and spatially between fields.

Figure 7: Calculated vertical stress gradients over the Baram Basin. Vertical stress varies with depth and spatially between fields.

Figure 8: Contour map of vertical stress gradients over the Baram Basin at $1500 \mathrm{~m}$ depth below the surface.

Figure 9: Contour map of vertical stress gradients over the Baram Basin at $1500 \mathrm{~m}$ depth below the sea bottom (or below the surface for onshore wells).

Figure 10: An example of a density reversal due to undercompaction associated with overpressure generated by disequilibrium compaction. Such abnormally low densities have resulted in low vertical stress magnitudes in some wells. 


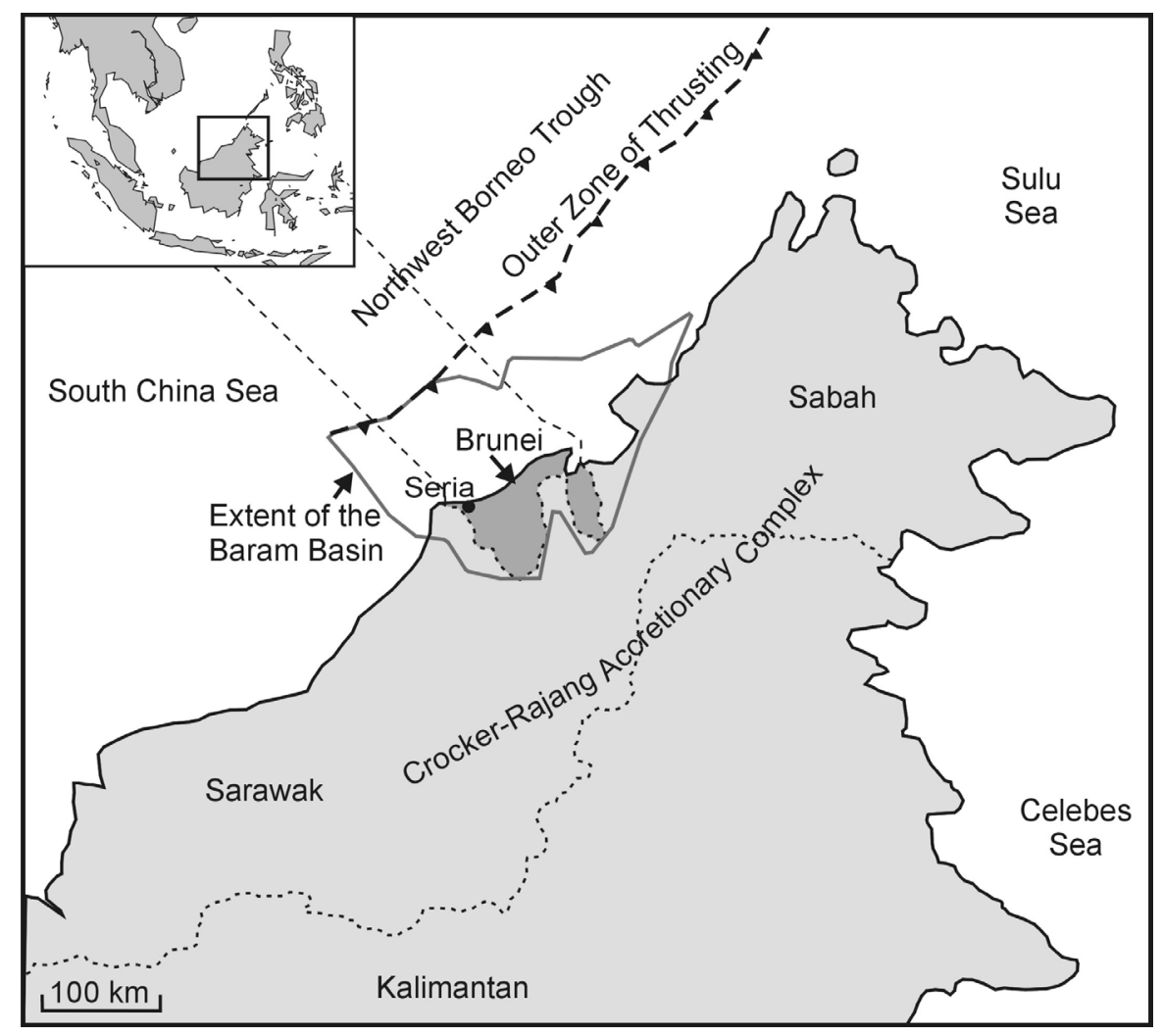

Figure 1 


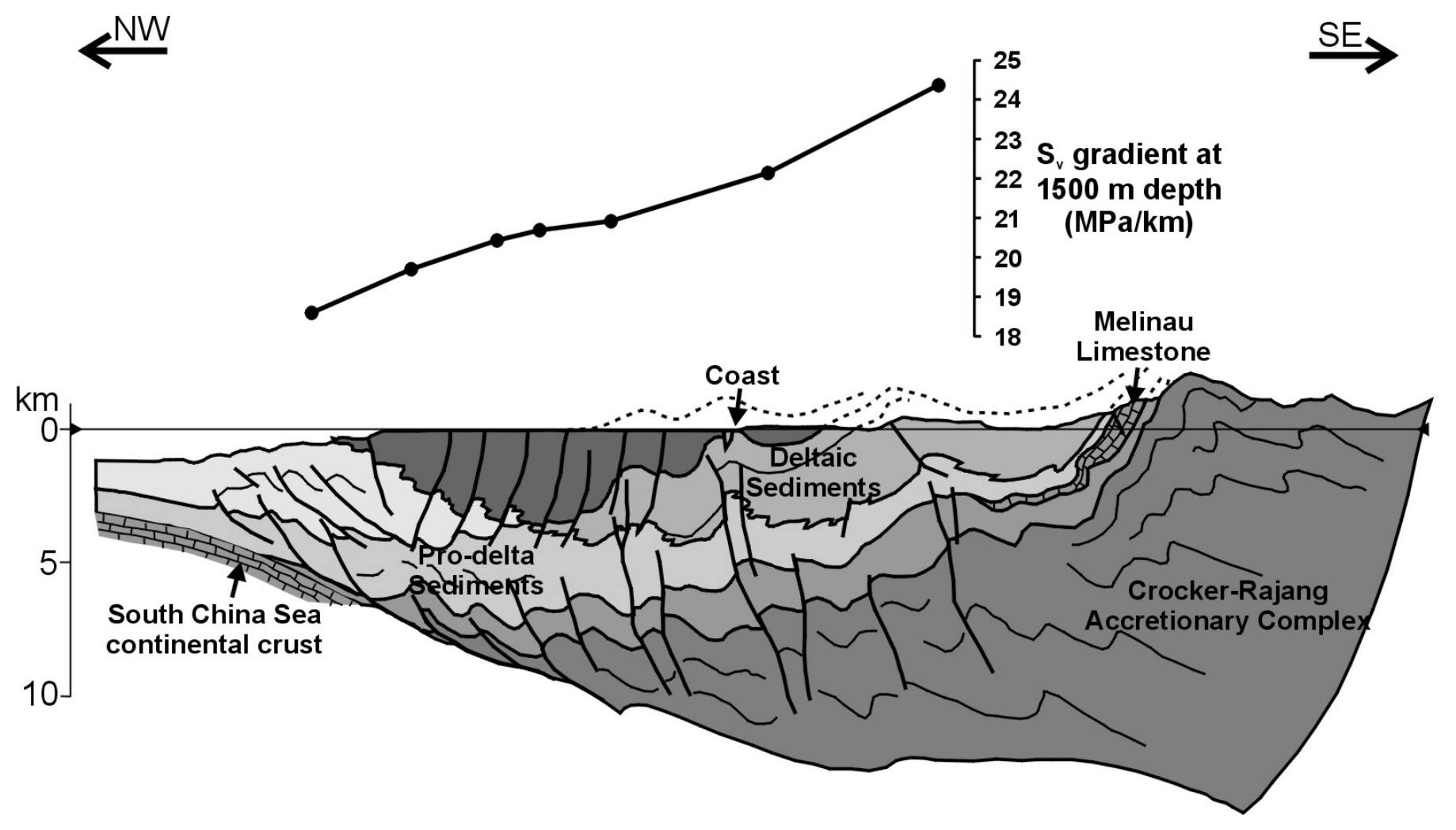

Figure 2 


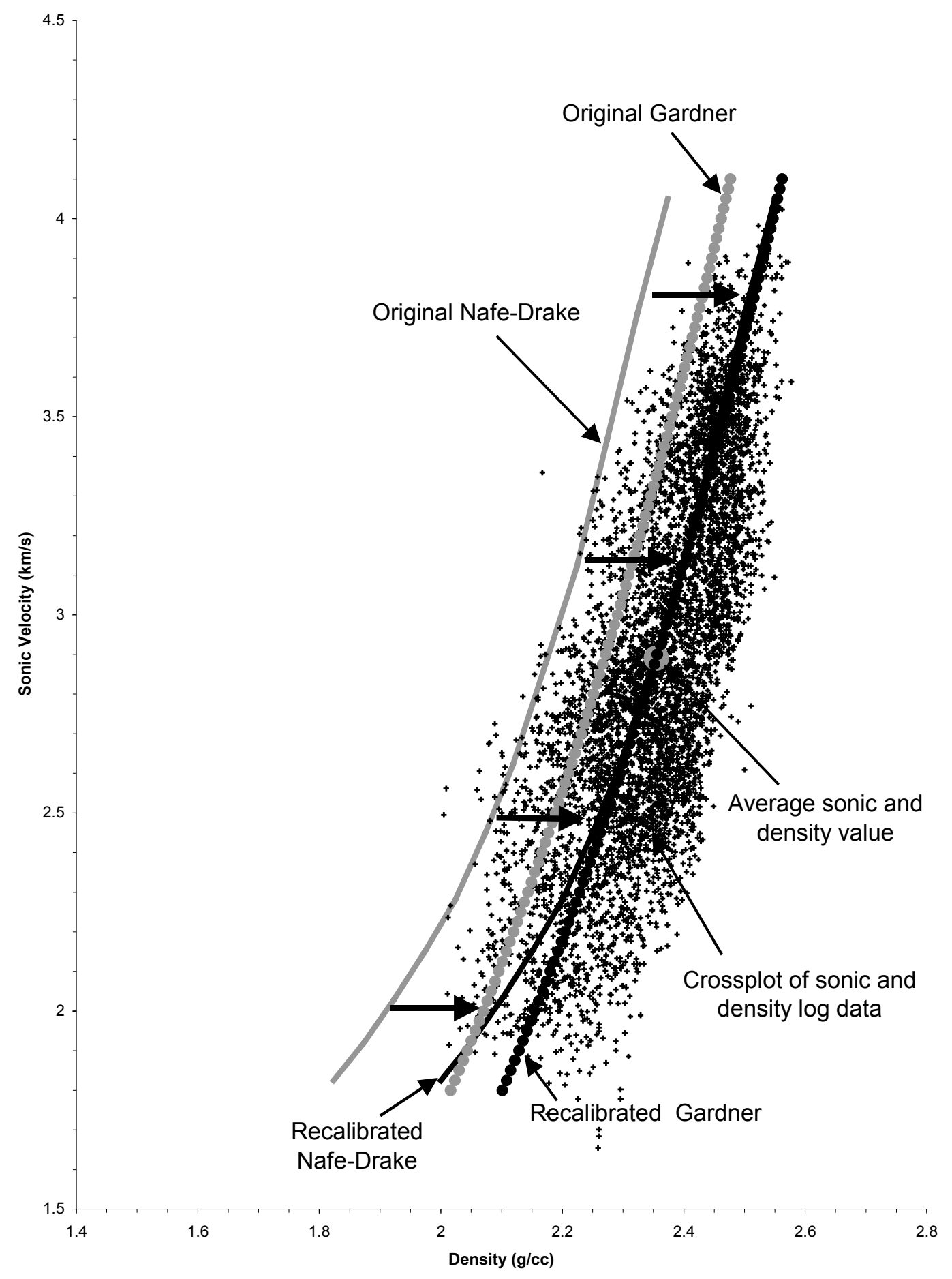

Figure 3 
(a) Density Error $\left(\mathrm{g} / \mathrm{cm}^{3}\right)$

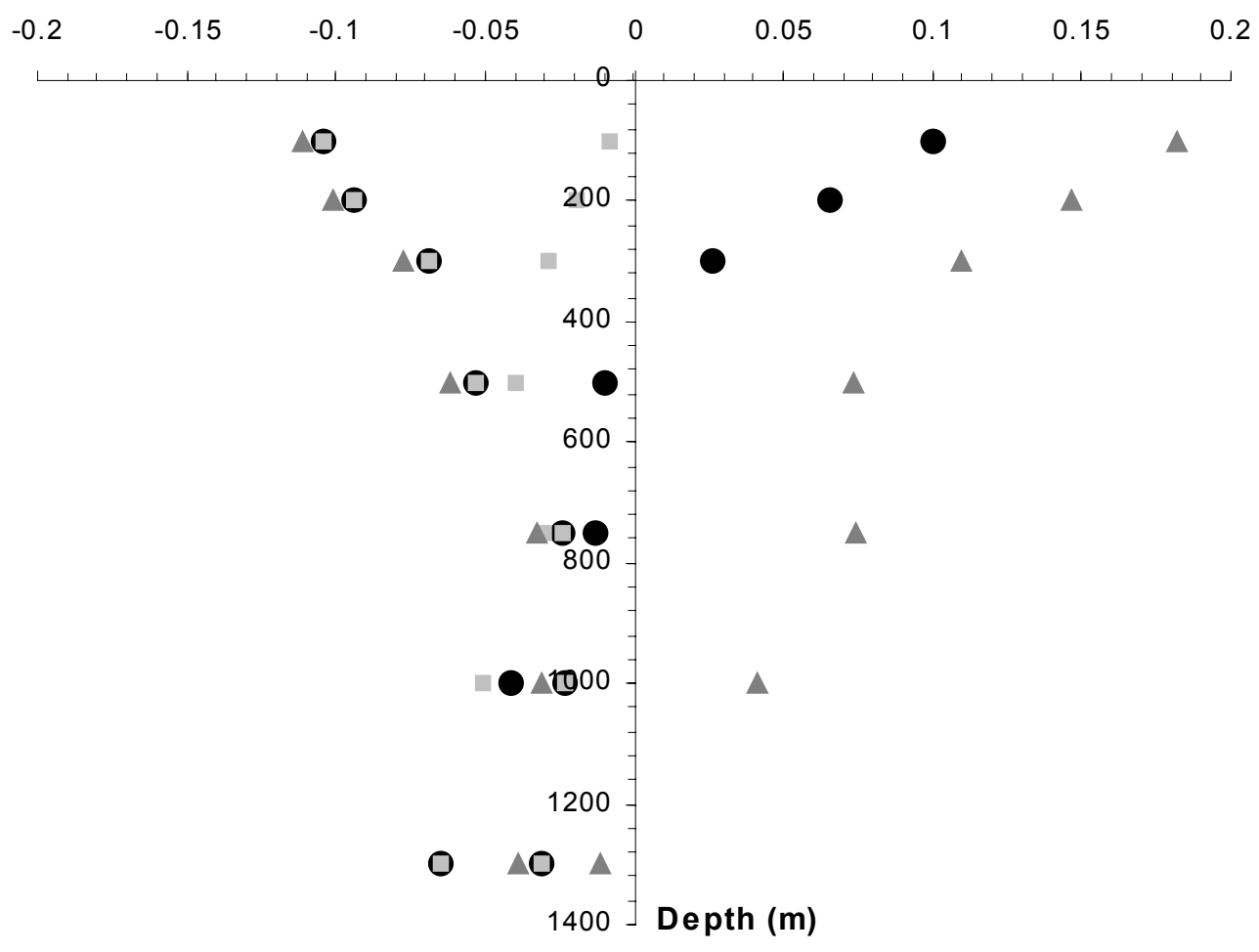

(b)

Vertical Stress Error (MPa)

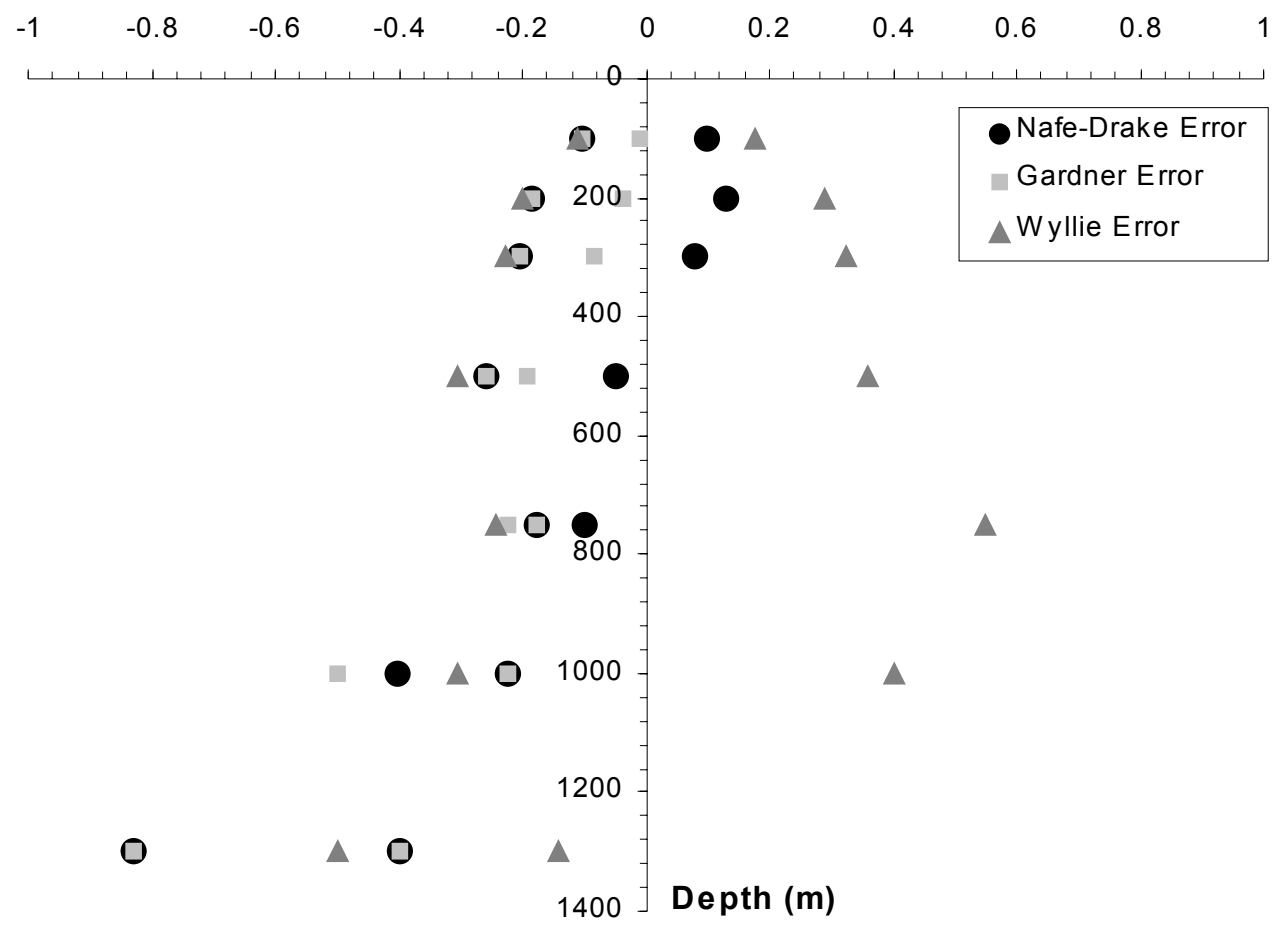

Figure 4 


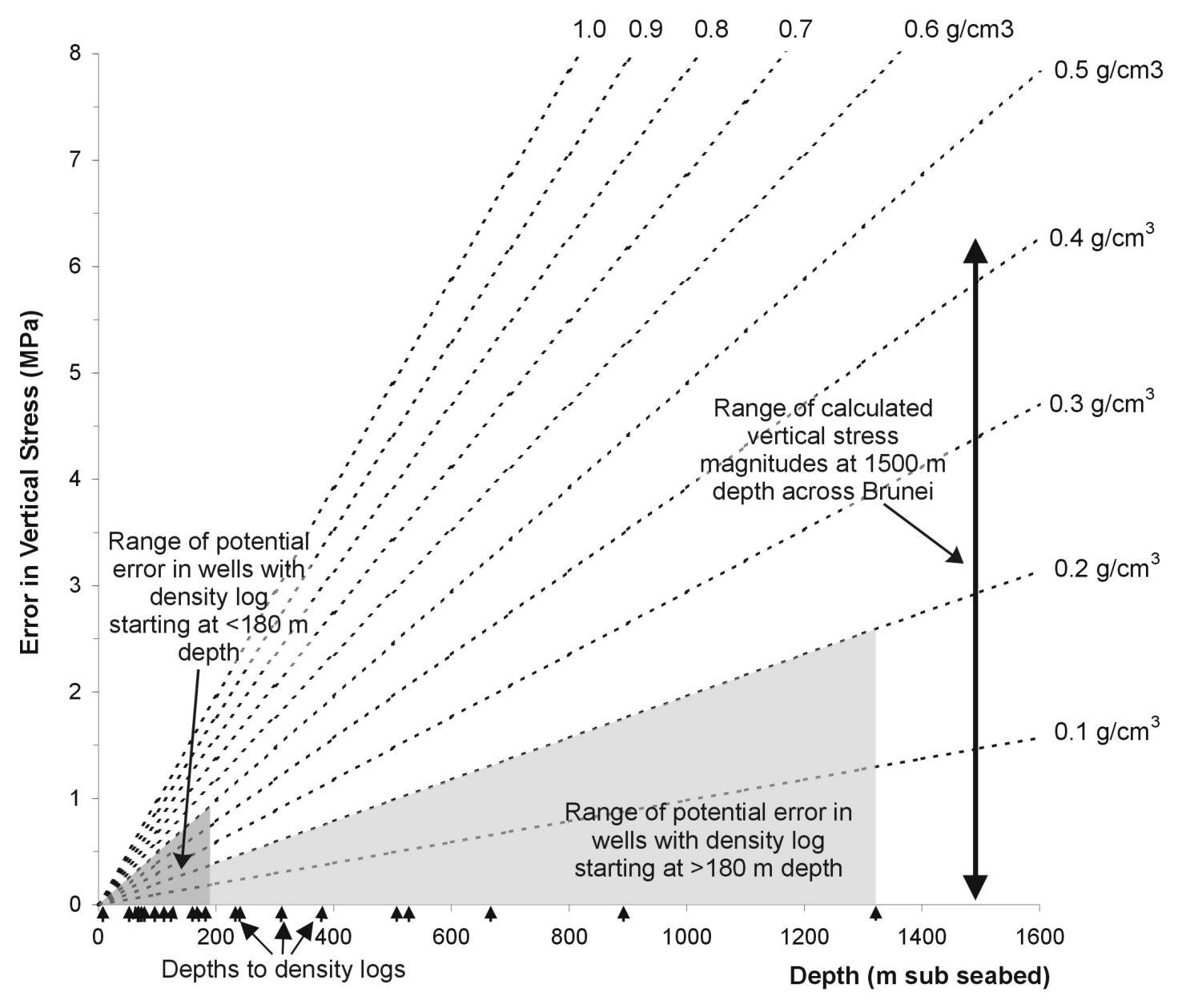

Figure 5 


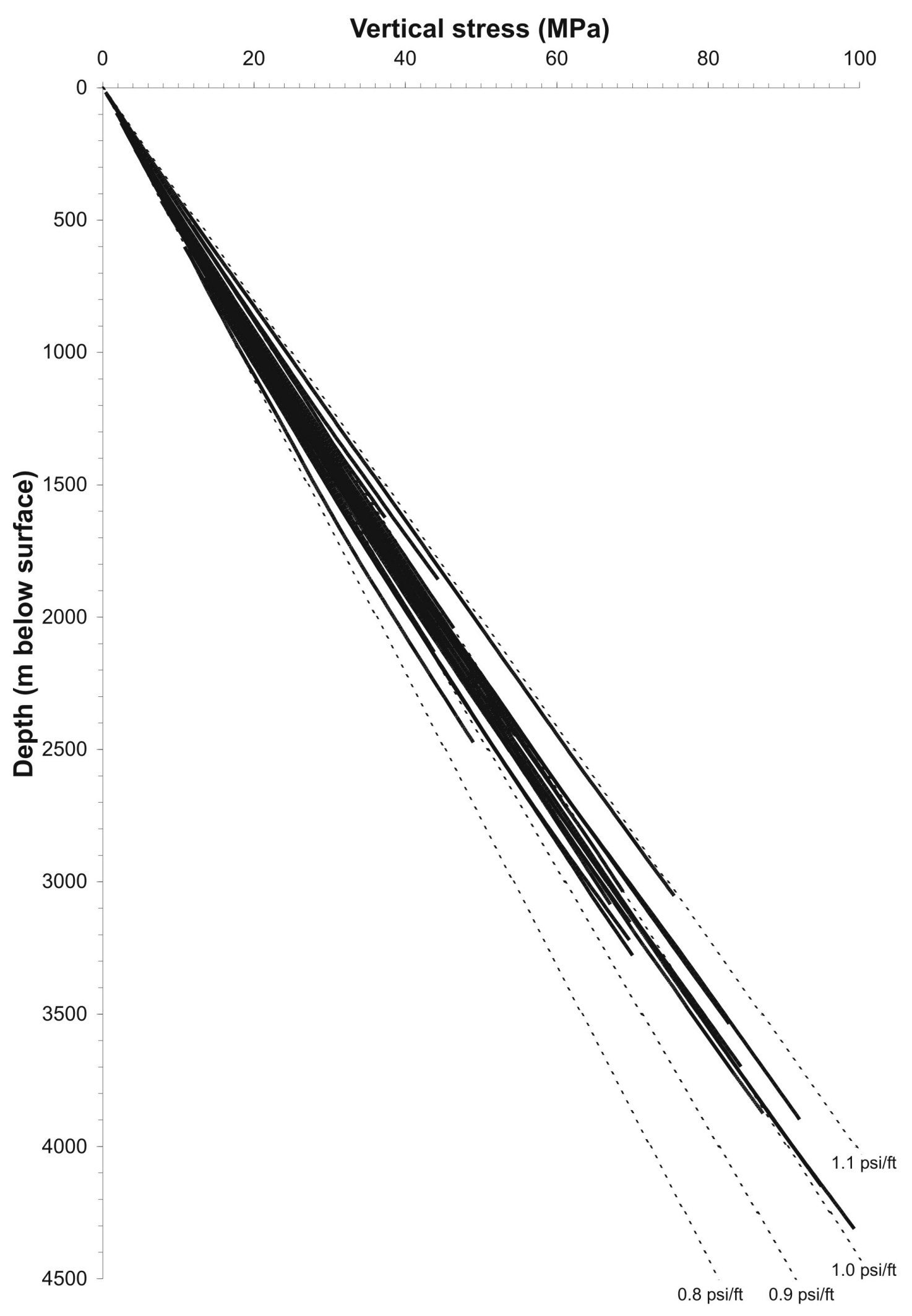

Figure 6 


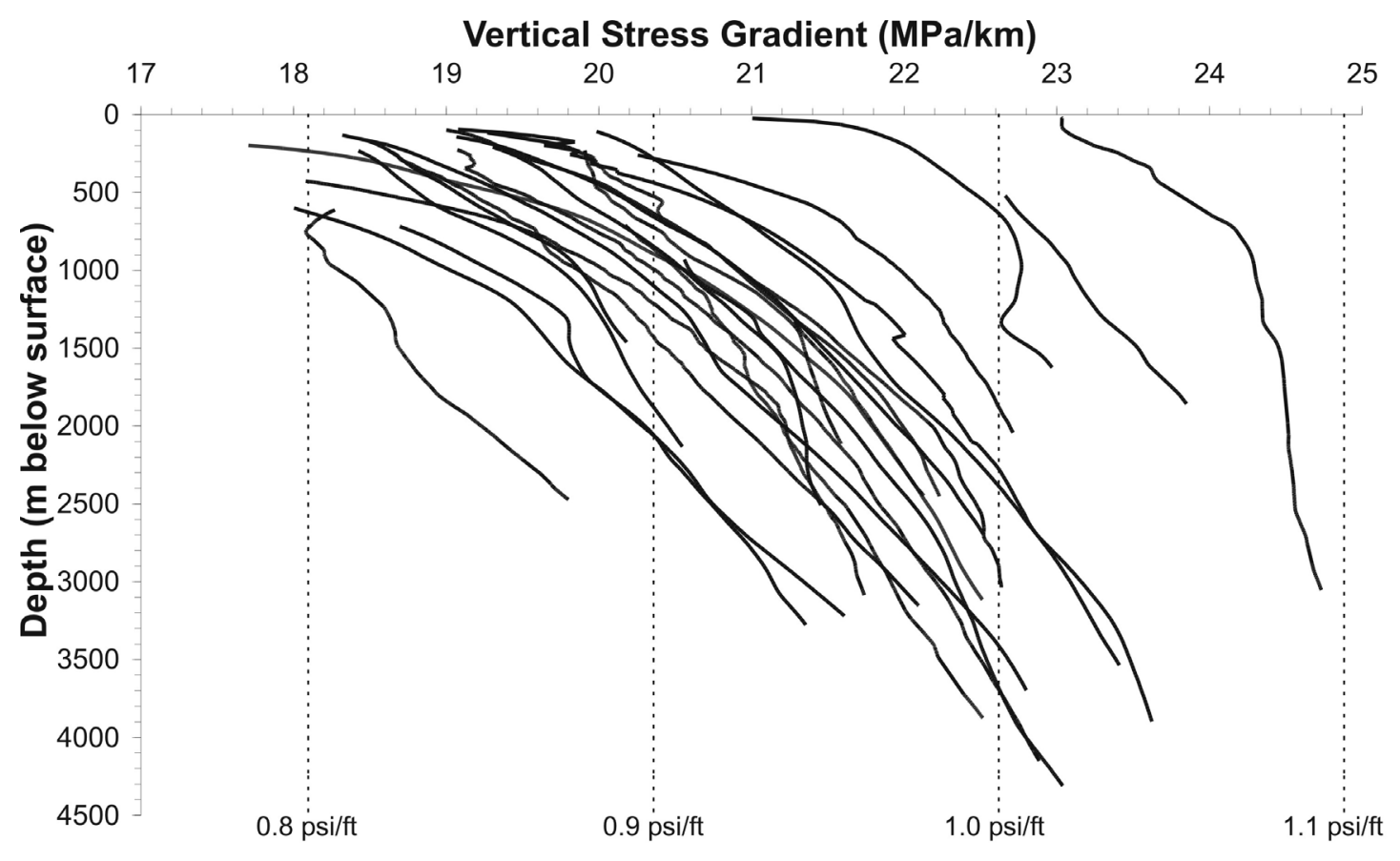

Figure 7 


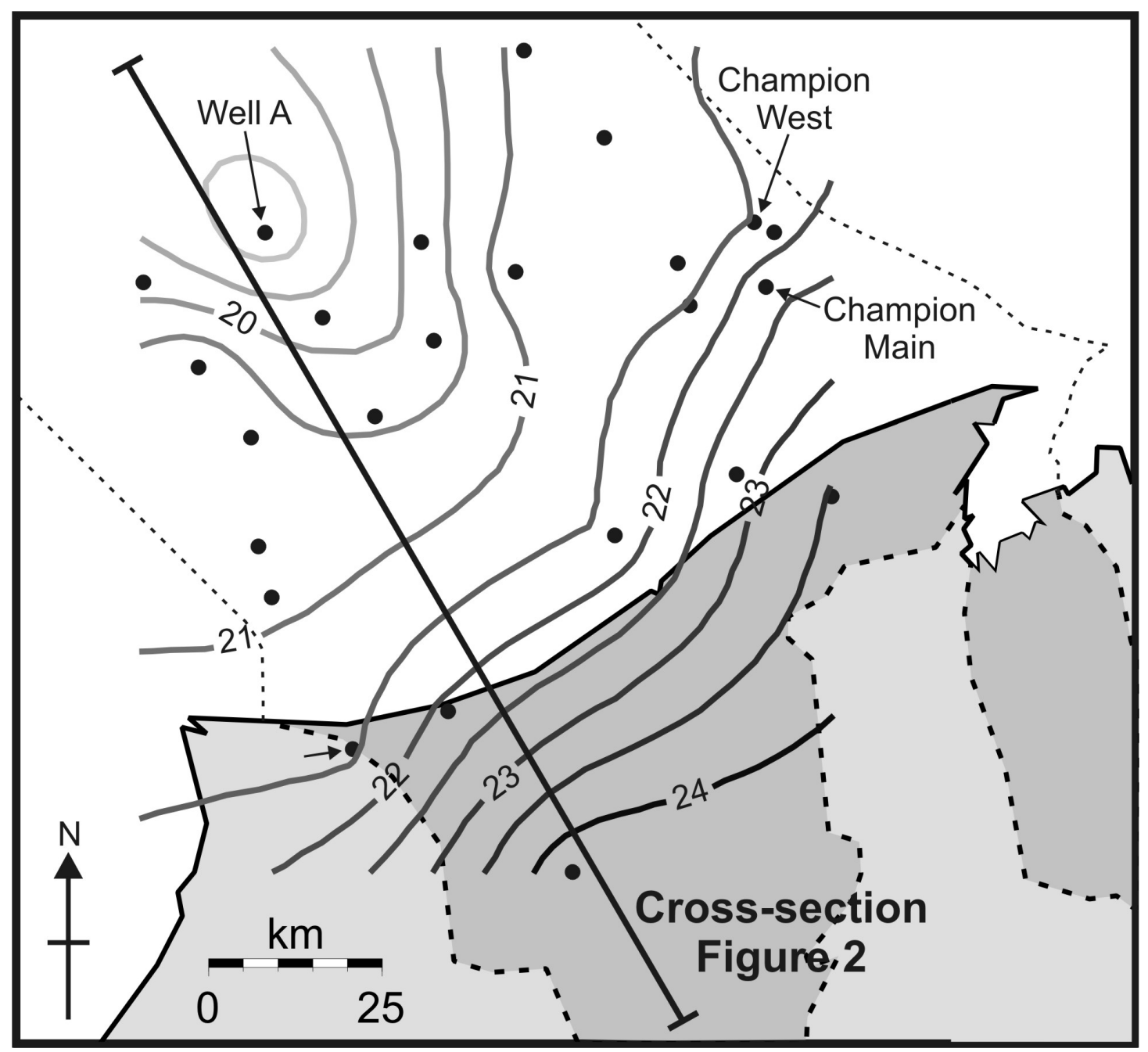

Figure 8 


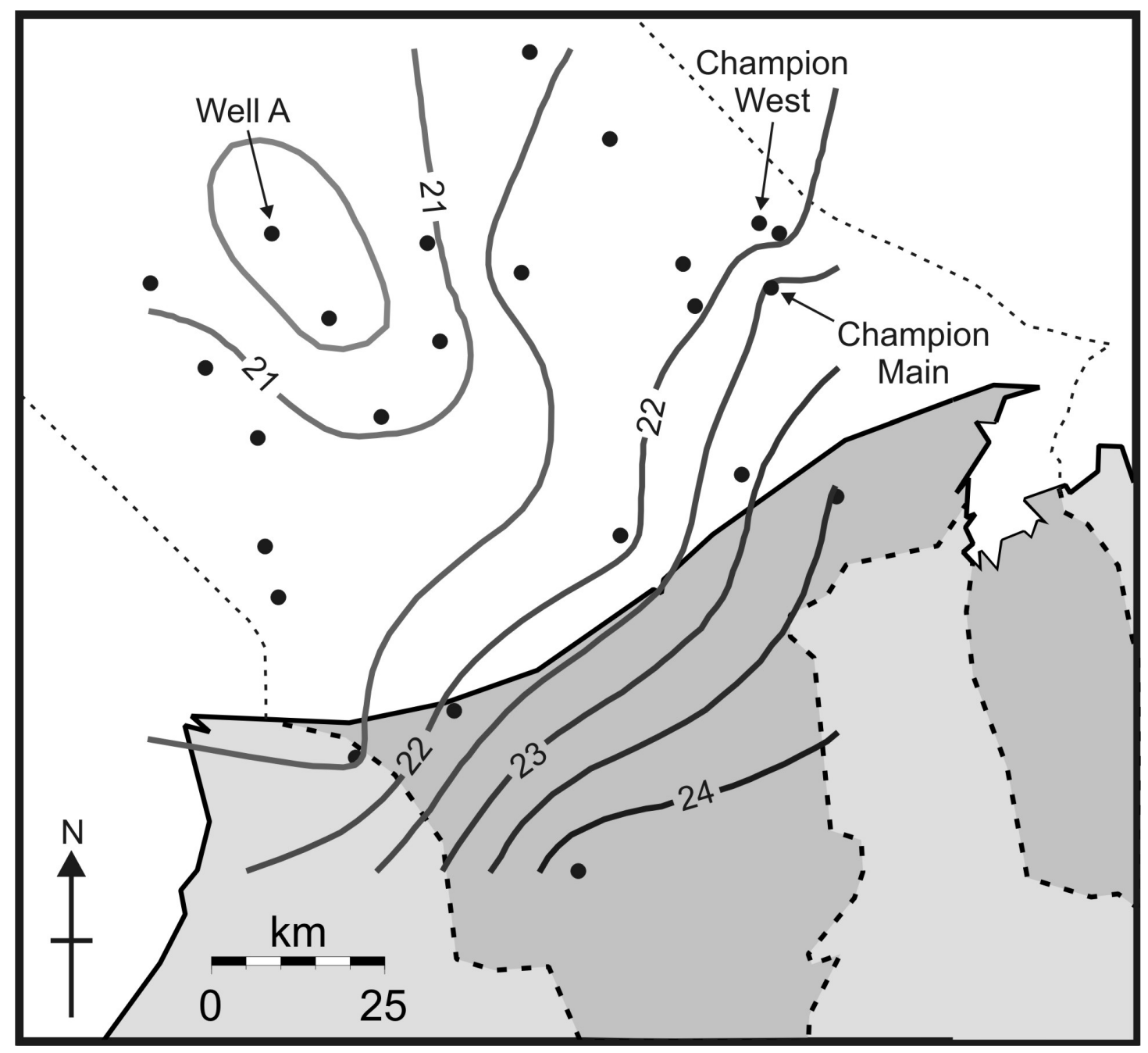

Figure 9 


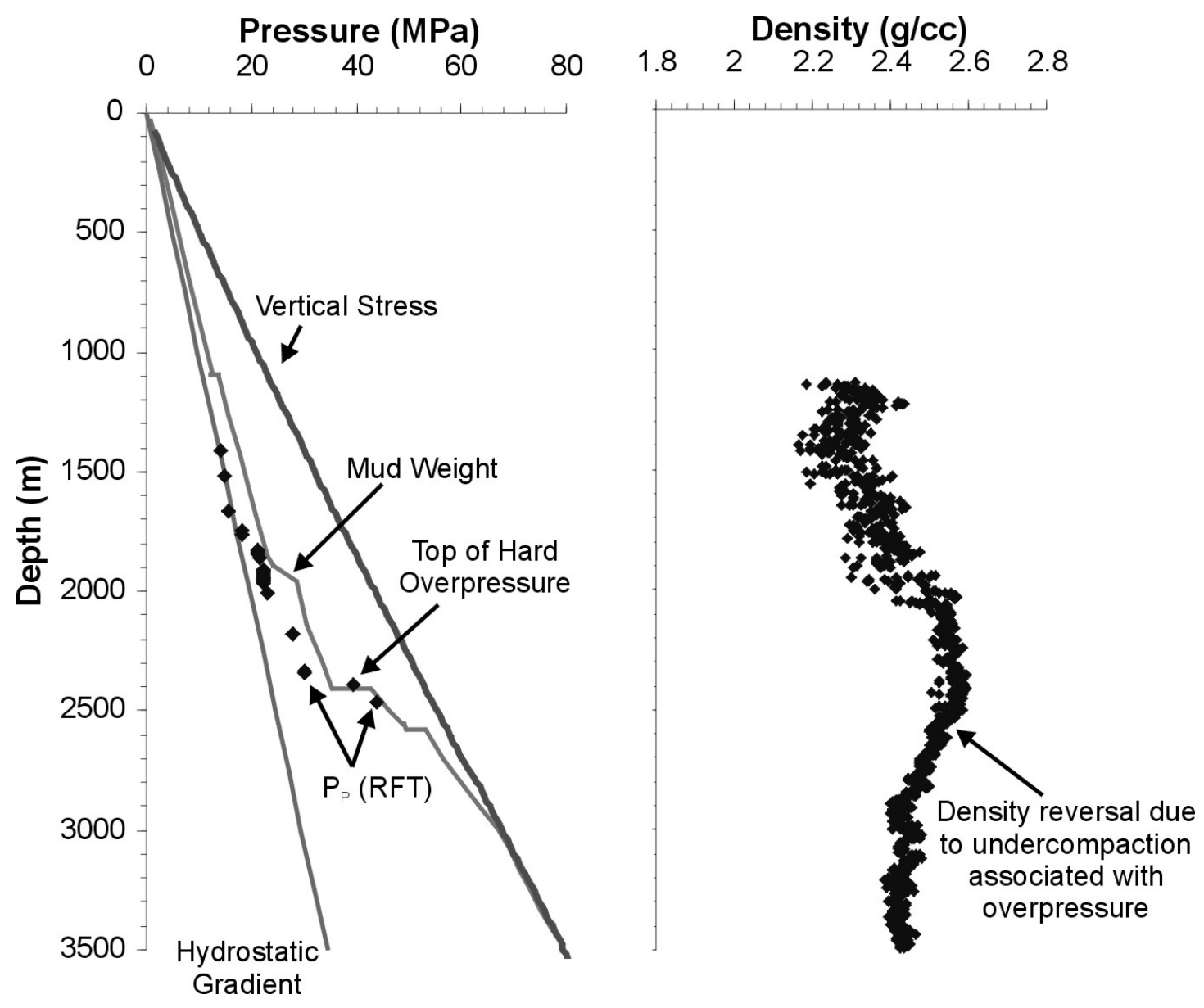

Figure 10 